\title{
Association between inflammatory markers and liver fat: The Multi-Ethnic Study of Atherosclerosis
}

\author{
Yasmin S. Hamirani, MD, \\ Cardiovascular Imaging Fellow, Los Angeles Biomedical Research Institute at Harbor-UCLA \\ Ronit Katz, DPhil \\ Ronit Katz, DPhil, \\ University of Washington, Seattle, WA \\ Khurram Nasir, MD, MPH, \\ Adjunct Assistant Professor of Medicine, Ciccarone Center for Preventive Cardiology, Johns \\ Hopkins University, Baltimore, MD \\ Irfan Zeb, MD, \\ Resident in Internal Medicine \\ Michael J. Blaha, MD, \\ Assistant Professor of Medicine, Ciccarone Center for Preventive Cardiology, Johns Hopkins \\ University, Baltimore, MD
}

Roger S. Blumenthal, MD, Professor of Medicine, Ciccarone Centre of Preventive Cardiology, Johns Hopkins University, Baltimore, MD

Richard N. Kronmal, PhD, and

University of Washington, Seattle, WA

\section{Matthew J. Budoff, MD}

Professor of Medicine, Los Angeles Biomedical Research Institute at Harbor-ULCA, Torrance, CA

\section{Abstract}

BACKGROUND—Nonalcoholic fatty liver disease (NAFLD) is a common liver disease. Data is emerging that an independent association between markers of subclinical atherosclerosis and NAFLD exists and it may be considered as an independent predictor of cardiovascular (CV) outcomes. We aim to better characterize the relationship between NAFLD and inflammatory markers in a multi-ethnic cohort by assessing fatty liver on computed tomography (CT) scans.

METHODS-The Multi-Ethnic Study of Atherosclerosis (MESA) is a longitudinal, populationbased study from four ethnic groups free of CV disease at baseline. The inflammatory markers studied include: C-reactive protein (CRP) and interleukin 6 (IL-6). On CT scans liver-to-spleen ratio (LSR: Hounsfield Units (HU) of the liver divided by HU of spleen) of $<1$ and liver

Corresponding Author: Yasmin Hamirani, MD 1124 West Carson Street, Torrance, CA, 90502 yasminshamshuddin@gmail.com Cell: 443-527-4766. 
attenuation of $<40 \mathrm{HU}$ were used as criteria for fatty liver. Unadjusted and adjusted multivariate linear and logistic regression analysis was performed.

RESULTS-4038 participants amongst 6814 MESA population with visible spleen on the CT scan, available CRP and IL-6 levels and no reported liver cirrhosis were included. The average age was $61+/-10$ years, 37\% Caucasians and $45 \%$ were males. Mean CRP and IL-6 were $2.36 \mathrm{mg} / \mathrm{dl}$ and $1.37 \mathrm{pg} / \mathrm{ml}$ respectively. 696 participants (17\%) had LSR of $<1$ and $253(6 \%)$ had liver attenuation of $<40 \mathrm{HU}$. When using LSR $<1$ as a continuous variable, the correlation (adjusted odds ratio (OR)) with CRP > 2.0 was 0.037 (95\% CI: 0.02-0.054) and with IL-6 was 0.014 (95\% CI: 0.004-0.023). On the other hand when presence and absence of LSR $<1$ was considered, higher ORs for association with CRP >2: 1.41 (95\% CI: 1.16 to 1.73) and IL6:1.18 (95\% CI: 1.05 to 1.31) were found. Similarly, the adjusted association of per unit decrease in liver attenuation with CRP>2 was 1.92 (95\% CI: 1.20 to 2.63) while for IL-6 was 1.08 (95\% CI: 0.69 to 1.47). When considering presence and absence of liver attenuation $<40 \mathrm{HU}$ the OR for CRP $>2$ was 2.27 (95\% CI: 1.62 to 3.16$)$ and for IL-6 was 1.33 (95\% CI: 1.13 to 1.58 ).

CONCLUSION-CRP and IL-6 levels were found to be significantly associated with liver fat assessed on CT scan after adjusting for other risk factors for atherosclerosis.

\section{Keywords}

Inflammation; Non-alcoholic fatty liver disease; computed tomography scan; $\mathrm{C}$ reactive protein

\section{Introduction}

In recent years alongside the obesity epidemic, the prevalence of Nonalcoholic fatty liver disease (NAFLD) has increased significantly around the globe ${ }^{1},{ }^{2}$. It includes different degrees of liver involvement ranging from fatty liver to nonalcoholic steatohepatitis (NASH), to hepatic cirrhosis and hepatocellular carcinoma. A strong association of NAFLD with metabolic syndrome ${ }^{3,4,5}, 6$ has been acknowledged. Despite presence of a significant overlap of NAFLD with all the classic risk factors of atherosclerosis (age, hyperlipidemia [elevated LDL, TG and low HDL], smoking, systolic blood pressure, family history of premature coronary artery disease $[\mathrm{CAD}]$, diabetes mellitus $[\mathrm{DM}]^{7}$ ) and fatty liver; data is emerging that NAFLD may be an independent predictor of cardiovascular disease (CVD) $)^{8},{ }^{9}$ as well as adverse cardiovascular (CV) outcomes ${ }^{10,11}$. Elevated serum markers of inflammation are shown to be associated with coronary artery disease (CAD $)^{12},{ }^{13}$. Now, with ongoing research in this area, NAFLD, assessed using elevated liver enzymes or by imaging, is linked to both coronary artery calcification (CAC) as well as with subclinical inflammatory markers of atherosclerosis ${ }^{14,15,16}$; independent of abdominal obesity.

A computed tomography (CT) scan of the chest has established itself as a useful tool to assess $\mathrm{CAC}^{17}$ and to assess for coronary plaque with contrast enhanced imaging ${ }^{18}$. IL-6 has been shown to be associated with insulin resistance in obese individuals with and without diabetes ${ }^{19}$ and has been proposed as a mediator of NAFLD ${ }^{20}$. Similarly, CRP has been related in multiple studies to inflammation and to liver steatosis ${ }^{21}$. In the MESA cohort, where noncontract CT scans are performed to assess for CAC; in patients where upper 
abdomen was included in the scan, we aim to look at the association of inflammatory markers (CRP and IL-6) with CT assessment of NAFLD.

The goal of our study is to determine, if by extending the scanned area, during CAC assessment, to include the upper abdomen (liver and spleen); with an insignificant increase in radiation exposure, a more comprehensive CAD risk assessment can be performed. We aim to better characterize the relationship of NAFLD with inflammatory markers, in a large multi-ethnic population based cohort.

\section{Methods}

\section{MESA study population}

The Multi-Ethnic Study of Atherosclerosis (MESA) is a longitudinal, population-based study of 6,814 men and women aged 45-84 years, from four ethnic groups free of CV disease at baseline recruited from 6 US communities (Baltimore, MD; Chicago, IL; Forsyth County, NC; Los Angeles County, CA; Northern Manhattan, NY; and St. Paul, MN). Baseline CAC scores were measured. Information about age, gender, ethnicity, and medical history was obtained by questionnaires. Current smoking was defined as having smoked a cigarette in the last 30 days. Alcohol consumption was assessed using three questions, ever consumed alcohol (Yes/No)?; currently drinking (Yes/No)?; and what was the largest \# of drinks in one day in the past month? Alcohol consumption was categorized in three groups based on ever consumption and largest number of drinks per day: no consumption or moderate consumption ( $0-1$ drinks/day for women and 0-2 drinks/day for men), high consumption (2-3 drinks/day for women and 3-4 drinks/day for men) and heavy drinking (defined as 4+ drinks/day for women and 5+ drinks/day for men). DM was defined as a fasting glucose $>126 \mathrm{mg} / \mathrm{dL}$ or use of hypoglycemic medications. Use of antihypertensive and other medications was based on clinical staff entry of prescribed medications verified by the staff. Resting blood pressure was measured 3 times in the seated position, and the average of the second and third readings was recorded. Hypertension was defined as a systolic blood pressure $>140 \mathrm{~mm} \mathrm{Hg}$, diastolic blood pressure $>90 \mathrm{~mm} \mathrm{Hg}$, or use of medication prescribed for hypertension. Body mass index (BMI) was calculated from the equation weight $(\mathrm{kg}) /$ height $(\mathrm{m} 2)$. Total and high-density lipoprotein cholesterol were measured from blood samples obtained after a 12-hour fast. Low-density lipoprotein cholesterol was estimated by the Friedewald equation ${ }^{22}$.

\section{Cardiac Computed tomography (CCT) Image Acquisition in the MESA study}

The computed tomography scanning of the chest was performed either with an ECGtriggered (at $80 \%$ of the RR interval) electron-beam computed tomography scanner (Chicago, Los Angeles, and New York field centers; Imatron C-150, Imatron, San Francisco, CA) or with prospectively ECG-triggered scan acquisition at 50\% of the RR interval with a multidetector computed tomography system that acquired 4 simultaneous 2.5-mm slices for each cardiac cycle in a sequential or axial scan mode (Baltimore, Forsyth County, and St. Paul field centers; LightSpeed, General Electric, Piscataway, NJ, or Volume Zoom, Siemens, New York, NY). Each participant underwent two consecutive nonenhanced cardiac computed tomography scans during a single session during breath hold to 
reduce motion artifacts and improving image quality of the coronary arteries. Each scan was performed from carina to below the apex of the heart that contains images of the liver and spleen. The protocol of scanner parameters and scanning details are reported previously ${ }^{23}$.

\section{Measurement of Inflammatory markers and other laboratory testing- MESA study}

The inflammatory markers studied include: CRP and IL-6. Fasting blood was drawn, processed and stored using standardized procedures. CRP was measured using a BNII nephelometer ( $\mathrm{N}$ high sensitivity CRP; Dade Behring Inc.). The intra-assay coefficients of variation (CoVs) were $2.3 \%-4.4 \%$ and the inter-assay $\mathrm{CoVs}$ were $2.1 \%-5.7 \%$ with a detection level of $0.18 \mathrm{mg} / \mathrm{L}$.A CRP level $>=2 \mathrm{mg} / \mathrm{L}$ was chosen as the cut-off for significant inflammation used to determine eligibility in the Justification for the Use of Statins in Prevention: An Intervention Trial Evaluating Rosuvastatin (JUPITER) clinical trial $^{24}$. IL-6 was measured using ultra-sensitive ELISA (Quantikine HS Human IL-6 Immunoassay; R\&D Systems, Minneapolis, MN) with an analytical CoV of $6.3 \%$ and a detection level of $0.04 \mathrm{pg} / \mathrm{mL}$. Plasma lipids including high-density lipoprotein (HDL) cholesterol and triglycerides were measured using the Roche Hitachi 911 analyzer (Roche Diagnostics, Indianapolis, IN).

\section{MESA population included in our study}

Amongst the total MESA population of 6814 participants, 2425 participants without visible liver or spleen on CT scan were excluded. Another 220 participants with excessive alcohol use, 7 self- reported cirrhosis, 31 with missing CRP and 93 with missing IL-6 values were excluded. Total number of participants included in our study was 4038 .

Liver Fat Measurement on CCT-Two readers analyzed the scans independently blinded to the demographic data. Both scans for each participant were examined, the scan with the largest span was selected for measurement of liver fat. Hepatic and splenic HU attenuation values were measured using regions of interest (ROI) greater than $100 \mathrm{~mm}^{2}$ in area. There were two ROI placed in the right liver lobe antero-posteriorly, one ROI in the left liver lobe and one ROI in the spleen. ROI with larger areas were used, whenever possible, to include a greater area of the liver and spleen with caution to exclude regions of non-uniform parenchymal attenuation, including hepatic vessels (Figure 1). L/S ratio was calculated by taking mean HU measurement of both liver lobes ROIs and dividing it by the spleen HU measurement. To provide an internal control, the mean splenic attenuation was also calculated by averaging three random ROI values of splenic attenuation on three transverse sections at different splenic levels (one ROI per section). L/S ratio $<1.0$ was taken as the cut- point for the diagnosis of presence of liver fat. As another parameter, liver attenuation $<40 \mathrm{HU}$ was used as a cutoff of $>30 \%$ liver fat content. A high inter and intra observer reproducibility of liver and spleen attenuation measurements was found ${ }^{25}$.

\section{Statistical Analysis}

NAFLD on CCT was defined using L/S ratio $<1.0$ and liver attenuation $<40 \mathrm{HU}$. Comparisons between $\mathrm{L} / \mathrm{S}$ ratio $<1.0$ with demographic measures and cardiovascular risk factors were expressed using means and proportions. We used the Chi square test for proportions and t-tests for comparing levels of continuous risk factors. 
To evaluate the association between inflammatory markers and NAFLD, we used multivariate linear and logistic regression. CRP and IL-6 were modeled continuously and due to their skewness were both $\log$ transformed to the base 2 to allow for easier interpretation (per doubling of biomarker). Models were adjusted for age, gender, race/ ethnicity and education and additionally for CV risk factors ([Body mass index BMI], smoking, hypertension, diabetes, low density lipoprotein [LDL] cholesterol, HDL, and lipidlowering medications) triglycerides and blood glucose.

Statistical analyses were performed with SPSS 16.0.2 software for Windows (SPSS Inc, Chicago, Illinois). A p-value $<0.05$ was considered statistically significant. Confidence intervals are expressed as $95 \%$ confidence intervals.

\section{Results}

The demographic data for our participant population is given in Table 1, The average age was $61+/-10$ years, 37\% Caucasians and 45\% were males. Mean CRP and IL-6 were 2.36 $\mathrm{mg} / \mathrm{dl}$ and $1.37 \mathrm{pg} / \mathrm{ml} .696$ participants (17\%) had LSR of $<1$, while 253 participants (6\%) had liver attenuation of $\mathrm{HU}<40$. A trend toward higher education associated with LSR $\geq 1$ was noted. $25 \%$ of the participants with LSR $<1$ vs. $18 \%$ in the $\geq 1$ group had less than high school level education, whereas $28 \%$ vs. $35 \%$ in each group respectively had college or more level education. In regards to ethnicity more Hispanics were found to have decreased LSR. No differences in smoking were identified in patients with any without fatty liver. Similarly, LSR < 1 was significantly more common with: lower HDL, higher TG, increased waist circumference and random sugar levels.

Significantly increased CRP and IL-6 levels were seen in patients with lower LSR. The median CRP $(\mathrm{mg} / \mathrm{ml})$ in patients with LSR <1 was 2.94(IQR: 1.37-6.28) vs. 1.79 (IQR: 0.81-1.87) in participants with LSR $\leq 1, \mathrm{p}<0.001$. Similarly, the median IL-6 $(\mathrm{mg} / \mathrm{ml})$ was 1.52 (IQR:1.02-2.37) vs. 1.23(IQR:0.78-1.87) in these groups respectively, $\mathrm{p}<0.001$.

Table 2 and 3 shows the association of CRP and IL- 6 with fatty liver on CCT. In table 2 CRP and IL6 are used as continuous variables, with values expressed as per unit increase or decrease. In table 3, CRP and IL6 are expressed as dichotomous variables.

\section{Association of LSR $<1$ with CRP $>2$ and IL-6: (Table 2\& 3)}

For LSR $<1$ (continuous variable), the adjusted odds ratio (OR) for association with CRP $>2.0$ was 0.037 (0.02-0.054) while with IL-6 was 0.014 (0.004-0.023). For LSR $<1$ as a dichotomous variable the association with CRP >2 was 1.41 (1.16 to 1.73) and for IL6 was 1.18 (1.05 to 1.31$)$.

\section{Association of liver $\mathrm{HU}<40$ with CRP $>2$ and IL-6: (Table 2\& 3)}

Adjusted OR for the association of per unit decrease in liver attenuation with CRP $>2$ was 1.92 (1.20 to 2.63) while for IL-6 was 1.08 (0.69 to 1.47). Using liver attenuation $<40 \mathrm{HU}$ as a dichotomous variable the OR with CRP >2 was 2.27 (1.62 to 3.16) and for IL-6 was 1.33 (1.13 to 1.58$)$. 
Table 3b shows the relationship of both LSR $<1.0$ and liver attenuation $<40$ with increasing quartiles of CRP and IL-6. With increasing quartiles of CRP and IL-6, higher OR for the association was seen. Adjusted for all the traditional risk factors for atherosclerosis, an increase in CRP was associated with increased OR for both LSR $<1$ and liver $\mathrm{HU}<40$. As CRP increased from $<0.85$ to $>4.26$, the prevalence (OR) of LSR $<1$ and liver $\mathrm{HU}<40$, increased from 1.09 to 1.66 and 0.95 to 2.51 respectively. Similarly, an increase in IL-6 from $<0.79$ to $>1.89$ was associated with increase in OR for association with LSR $<1$ from 1.48 to 1.75 and an increase in prevalence of $\mathrm{HU}<40$ from 1.25 to 2.41 .

\section{Discussion}

In a large multi-ethnic cohort of MESA participants, our study shows an independent, significant association between inflammatory markers and liver fat measured on computed tomography (CCT). This association was found to be stronger with increasing levels of CRP and IL-6.

NAFLD is increasingly detected, on liver biopsy, liver function analysis and imaging studies inclusive of: abdominal ultrasound, CT, magnetic resonance angiography (MRA) and spectroscopy. ${ }^{26},{ }^{27}$. In our multi-ethnic population, the prevalence of fatty liver based on CT- LSR < 1 was $17 \%$. A significant overlap exists between NAFLD and other classic and non-traditional risk factors of atherosclerosis. In our participants, increased fatty liver was seen with increased BMI and with presence of DM and HTN.

In the present study, we did not look at the association of NAFLD with presence of CAD and major adverse cardiac events. However, in several longitudinal studies, NAFLD, like other CV risk factors, is seen as an independent predictor of cardiovascular disease (CVD), cerebrovascular disease, and its associated mortality and morbidity. In a study on type II diabetic individuals, presence of NAFLD significantly increased the prevalence of coronary ( $23 \%$ vs. $15.5 \%$ ), cerebrovascular (17.2\% vs. $10.2 \%$ ) and peripheral vascular disease $(12.8 \%$ vs. $7 \%)$. In pediatric obese population ${ }^{28}$ and in adults $29,30,31$. NAFLD was related to significantly increased carotid artery intima-media thickness (IMT). It has also been shown to be an independent predictor of calcific and noncalcific non-obstructive coronary plaque ${ }^{20}$. In the Jackson heart study ${ }^{32}$, conducted in African Americans, where non contrast CT scan was used to assess for fatty liver, liver attenuation per 1 standard deviation decrement was associated inversely with CAC in multivariable-adjusted models (OR 0.89,95\% CI: $0.8-0.9, \mathrm{p}=0.01$ ).

Several small studies in patients with NAFLD in which long term follow up was performed, CVD was the second most common cause of death ${ }^{33},{ }^{34}$. In an Olmsted county study ${ }^{35}$, the overall mortality of 420 NAFLD patients was significantly increased over a mean follow-up of 7.6 years compared to the general population, and CVD was among the most common causes of death. This finding was repeatedly noticed in the NHANES III participants ${ }^{36}, 37$.

NAFLD is characterized as a chronic inflammatory condition, however, it remains unclear and controversial as to if it is related to, or, independent of the presence of visceral adiposity. Our study agrees with the prior work that has shown an independent association 
of fatty liver with inflammatory markers, which explains the increased prevalence of cardiovascular morbidity and mortality in patients with NASH. Van Der Poorten ${ }^{38}$ identified visceral fat volume (assessed by MRA) and IL- 6 to be independently associated with inflammation and fibrosis. Similarly, Kolak et $a l^{39}$ noted adipose tissue inflammation to be present only in individuals with hepatic steatosis independent of obesity. This suggests inflammation to be dependent on NAFLD or NAFLD causing inflammation and leading to CVD. In our study, IL-6 and CRP were used as markers of inflammation. Wieckowska et al, found IL- 6 and CRP levels, in the presence of hepatic steatosis to be associated with higher degree of liver fibrosis and inflammation ${ }^{40}$. In overweight, male patients with biopsy proven NAFLD, presence of Inflammation was directly associated with NAFLD, independent of visceral obesity ${ }^{41},{ }^{42},{ }^{43},{ }^{44},{ }^{45}$. Jackson heart study ${ }^{35}$ found no interaction between liver attenuation on CCT and abdominal visceral fat when looking at the prevalence of CAC. Ndumele ${ }^{16}$ in a recent study on 2388 patients, found a significantly high independent association of hepatic steatosis on liver ultrasound (OR 2.07(1.68-2.56) with hsCRP >3 $\mathrm{mg} / \mathrm{L}$. Hepatic steatosis when combined with other traditional risk factors of atherosclerosis was found to cause an additive increase in hsCRP is. We believe that regardless of abdominal adiposity, an inflamed fatty liver produces further pro-inflammatory cytokines with atherogenic effects on both cardiovascular and cerebrovascular system. This knowledge holds great clinical utility and can help plan preventive and therapeutic strategies.

Liver biopsy with limitations due its invasiveness is currently the gold standard for diagnosing NAFLD. There are constraints associated with all the non-invasive imaging modalities in regards to assessment for NAFLD. For example, the ultrasound gives accurate assessment of fatty liver, when $>33 \%$ of the liver is affected ${ }^{46}$. Liver fat on CCT was found to have a sensitivity and specificity of $78 \%$ and $72 \%$ respectively (using magnetic resonance spectroscopy as a gold standard), to assess for hepatic steatosis ${ }^{47}$. We propose, that since noncontrast CT is widely available and used for the evaluation of CAC in asymptomatic low to intermediate Framingham risk patients ${ }^{48}$, it can also be utilized as a further risk restratification tool, based on the assessment of fatty liver, without additional radiation exposure or expense from already acquired data.

\section{Limitations}

Non-contrast computed tomography was the primary and only assessment tool in our study, as it relates to the assessment of liver fat. No comparison with any other non-invasive imaging modality or liver biopsy was performed. In the MESA participants, liver enzymes were not measured, and thus were unavailable as laboratory markers in our study. Additionally, in the MESA study, the data on secondary causes of hepatic steatosis, other than alcohol use were not measured. The alcohol intake was measured in drinks/day with the exact grams of alcohol consumed/day not determined. No outcome analyses were performed based on liver fat assessment. Only two inflammatory markers were analyzed for the association. The association of liver fat and inflammatory markers was not studied with the presence of coronary artery calcium and with metabolic syndrome. However these are addressed in future studies on the MESA population. 


\section{Conclusion}

In a large multi-ethnic cohort, our study showed a significant independent association between IL-6 and CRP and liver fat measured on computed CT scan with strengthening relationship with increasing levels of IL-6 and CRP. It is possible to obtain additional information as it relates to fatty liver on CT scan at the time of CAC measurement. This would help us further risk stratify asymptomatic individuals with low to intermediate risk for $\mathrm{CAD}$, based on traditional risk categorization. Future large population based studies need to be performed, to reproduce the same results, before liver fat can be used as one of markers for inflammation, cardiovascular atherosclerosis and CAD.

\section{References}

1. Hamaguchi M, Kojima T, Takeda N, et al. The metabolic syndrome as a predictor of non-alcoholic fatty liver disease. Ann Intern Med. 2005; 143:722-8. [PubMed: 16287793]

2. Zois CD, Baltayiannis GH, Bekiari A, et al. Steatosis and steatohepatitis in postmortem material from Northwestern Greece. World J Gastroenterol. 2010; 16:3944-9. 10. [PubMed: 20712056]

3. Athyros VG, Mikhailidis DP, Didangelos TP, et al. Effect of multifactorial treatment on nonalcoholic fatty liver disease in metabolic syndrome: a randomised study. Curr Med Res Opin. 2006; 22(5):873-83. [PubMed: 16709309]

4. Aygun C, Kocaman O, Sahin T, Uraz S, Eminler AT, Celebi A, Senturk O, Hulagu S. Evaluation of Metabolic Syndrome Frequency and Carotid Artery Intima-media Thickness as Risk Factors for Atherosclerosis in Patients with Nonalcoholic Fatty Liver Disease. Dig Dis Sci. 2007; 10:194-200.

5. Marceau P, Biron S, Hould FS, et al. Liver pathology and the metabolic syndrome X in severe obesity. Journal of Clinical Endocrinology and Metabolism. 1999; 84(5):1513-1517. [PubMed: 10323371]

6. Angelico F, Del Ben M, Conti R, et al. Non-alcoholic fatty liver syndrome: a hepatic consequence of commonmetabolic diseases. Journal of Gastroenterology and Hepatology. 2003; 18(5):588-594. [PubMed: 12702052]

7. Chen G, Brunt EM. Diabetic hepatosclerosis: a 10-year autopsy series. Liver Int. 2009; 29(7):104450. [PubMed: 19141031]

8. Targher G, Bertolini L, Padovani R, et al. Prevalence of Nonalcoholic Fatty Liver Disease and Its Association with Cardiovascular Disease among Type 2 Diabetic Patients. Diabetes Care. 2007; 30:1212-1218. [PubMed: 17277038]. [PubMed: 17277038]

9. Targher G, Bertolini L, Poli F, Rodella S, Scala L, Tessari R, Zenari L, Falezza G. Nonalcoholic fatty liver disease and risk of future cardiovascular events among type 2 diabetic patients. Diabetes. 2005; 54:3541-3546. [PubMed: 16306373]

10. Adams LA, Lymp JF, St Sauver J, Sanderson SO, Lindor KD, Feldstein A, Angulo P. The natural history of nonalcoholic fatty liver disease: a population-based cohort study. Gastroenterology. 2005; 129(1):113-21. [PubMed: 16012941]

11. Jepsen P, Vilstrup H, Mellemkjaer L. Prognosis of patients with a diagnosis of fatty liver--a registry based cohort study. Hepatogastroenterology. 2003; 50(54):2101-4. [PubMed: 14696473]

12. Ridker PM, Heeenkens CH, Buring JE, Rifai N. C reactive protein and toher markers of inflammation in the prediction of cardiovascular disease in women. N Eng J Med. 2000; 342:836843.

13. Blake GJ, Ridker PM. Novel clinical markers of vascular wall inflammation. Circ Res. 2001; 89:763-771. [PubMed: 11679405]

14. Berg AH, Scherer PE. Adipose tissue, inflammation, and cardiovascular disease. Circ Res. 2005; 96:939-49. [PubMed: 15890981]

15. Santos RD, Nasir K, Conceicao RD, Sarwar A, Carvalho JA, Blumenthal RS. Hepatic steatosis is associated with a greater prevalence of coronary artery calcification in asymptomatic men. Atherosclerosis. 2007; 194(2):517-519. [PubMed: 17335826] 
16. Ndumele CE, Nasir K, Conceicao RD, Carvalho J, Blumenthal RS, Santos RD. Hepatic steatosis, obesity and the metabolic syndrome are independently are additively associated with increased systemic inflammation. Arterioscler Thromb Vasc Biol. 2011; 31(8):1927-1932. [PubMed: 21546603]

17. Pletcher MJ, Sibley CT, Pignone M, Vittinghoff E, Greenland P. Interpretation of the Coronary artery calcium score in combination with conventional cardiovascular risk factors: The multiethnic Study of Atherosclerosis (MESA). Circulation. Jul 24.2013 [epub ahead of print].

18. Hoffmann U, Truong QA, Schoenfeld DA, Chou ET, Woodard PK, Nagurney JT, Pope JH, Hauser TH, White CS, Weiner SG, Kalanjian S, Mullins ME, Mikati I, Peacock WF, Zakroysky P, Hayden D, Goehler A, Lee H, Gazelle GS, Wiviott SD, Fleg JL, Udelson JE. ROMICAT-II Investigators. Coronary CT angiography versus standard evaluation in acute chest pain. N Engl J Med. 2012; 367(4):299-308. [PubMed: 22830462]

19. Bastard JP, Maachi M, Van Nhieu JT, Jardel C, Bruckert E, Grimaldi A, Robert JJ, Capeau J, Hainque B. Adipose tissue IL-6 content correlates with resistance to insulin activation of glucose uptake both in vivo and in vitro. J Clin Endocrinol Metab. 2002; 87(5):2084-2089. [PubMed: 11994345]

20. Kishimoto T. IL-6: from its discovery to clinical applications. Int Immunol. 2010; 22:347-352. [PubMed: 20410258]

21. Zimmermann E, Anty R, Tordjman J, Verrijken A, Gual P, Tran A, Iannelli A, Gugenheim J, Bedossa P, Francque S, Le Marchand-Brustel Y, Clement K, Van Gaal L, Sørensen TI, Jess T. Creactive protein levels in relation to various features of non-alcoholic fatty liver disease among obese patients. J Hepatol. Sep; 2011 55(3):660-665. [PubMed: 21238518]

22. Warnick GR, Knopp RH, Fitzpatrick V, Branson L. Estimating low-density lipoprotein cholesterol by the Friedewald equation is adequate for classifying patients on the basis of nationally recommended cutpoints. Clin Chem. 1990; 36(1):15-19. [PubMed: 2297909]

23. Assy N, Djibre A, Farah R, Grosovski M, Marmor A. Presence of Coronary Plaques in Patients with Nonalcoholic Fatty Liver Disease. Radiology. 2010; 254(2):393-400. [PubMed: 20093511]

24. Ridker PM, MacFadyen JG, Nordestgaard BG, et al. Rosuvastatin for primary prevention among individuals with elevated highsensitivity C-reactive protein and 5\% to $10 \%$ and $10 \%$ to $20 \% 10$ year risk: implications of the Justification for the Use of Statins in Primary Prevention: An Intervention Trial Evaluating Rosuvastatin (JUPITER) trial for "'intermediate risk.'. Circ Cardiovasc Qual Outcomes. 2010; 3:447-452. [PubMed: 20736443]

25. Zeb I. Computed Tomography Scans in the Evaluation of Fatty Liver Disease in a Population Based Study: The Multi-Ethnic Study of Atherosclerosis. Acad Radiol. 2012; 19(7):811-818. [PubMed: 22521729]

26. Kechagias S, Ernersson A, Dahlqvist O, et al. Fast-food-based hyperalimentation can induce rapid and profound elevation of serum alanine aminotransferase in healthy subjects. Gut. 2008; 57:649654. [PubMed: 18276725]

27. Sharma P, Martin DR, Pineda N, Xu Q, Vos M, et al. Quantitation analysis of T2 correction in single voxel magnetic resonance spectroscopy of hepatic lipid fraction. J. Magn. Reson. Imaging. 2009; 29:629-35. [PubMed: 19243059]

28. Pacifico L, Cantisani V, Ricci P, et al. Nonalcoholic fatty liver disease and carotid atherosclerosis in children. Pediatr Res. 2008; 63:423-427. [PubMed: 18356751]

29. Brea A, Mosquera D, Martin E, et al. Nonalcoholic Fatty Liver Disease Is Associated With Carotid Atherosclerosis: A Case-Control Study. Arterioscler Thromb Vasc Biol. 2005; 25:1045-1050. [PubMed: 15731489]

30. Targher G, Bertolini L, Padovani R, et al. Relation of Nonalcoholic Hepatic Steatosis to Early Carotid Atherosclerosis in Healthy Men: Role of visceral fat accumulation. Diabetes Care. 2004; 27:2498-2500. [PubMed: 15451925]

31. Sookoian S, Pirola CJ. Non-alcoholic fatty liver disease is strongly associated with carotid atherosclerosis: A systematic review. J Hepatol. 2008; 49:600-607. [PubMed: 18672311]

32. Liu J, Musani SK, Bidulescu A, Carr JJ, Wilson JG, Taylor HA, Fox CS. Fatty liver, abdominal adipose tissue and atherosclerotic calcification in African Americans: the Jackson Heart Study. Atherosclerosis. Oct; 2012 224(2):521-5. [PubMed: 22902209] 
33. Matteoni CA, Younossi ZM, Gramlich T, et al. Nonalcoholic fatty liver disease: a spectrum of clinical and pathological severity. Gastroenterology. 1999; 116:1413-1419. [PubMed: 10348825]

34. Ekstedt M, Franzén LE, Mathiesen UL, et al. Long-term follow-up of patients with NAFLD and elevated liver enzymes. Hepatology. 2006; 44:865-873. 873. [PubMed: 17006923]

35. Adams LA, Lymp JF, St. Sauver J, et al. The Natural History of Nonalcoholic Fatty Liver Disease: A Population-Based Cohort Study. Gastroenterology. 2005; 129:113-121. [PubMed: 16012941]

36. Ong JP, Pitts A, Younossi ZM. Increased overall mortality and liver-related mortality in nonalcoholic fatty liver disease. J Hepatol. 2008; 49:608-612. [PubMed: 18682312]

37. Dunn W, Xu R, Wingard DL, Rogers C, Angulo P, et al. Suspected nonalcoholic fatty liver disease and mortality risk in a population-based cohort study. Am. J. Gastroenterol. 2008; 103:2263-71. [PubMed: 18684196]

38. Van Der Poorten D, Milner KL, Hui J, Hodge A, Trenell MI, et al. Visceral fat: a key mediator of steatohepatitis in metabolic liver disease. Hepatology. 2008; 48:449-57. [PubMed: 18627003]

39. Kolak M, Westerbacka J, Velagapudi VR, Wågsäter D, Yetukuri L, Makkonen J, Rissanen A, Häkkinen AM, Lindell M, Bergholm R, Hamsten A, Eriksson P, Fisher RM, Oresic M, YkiJärvinen $\mathrm{H}$. Adipose tissue inflammation and increased ceramide content characterize subjects with high liver fat content independent of obesity. Diabetes. Aug; 2007 56(8):1960-8. [PubMed: 17620421]

40. Wieckowska A, Papouchado BG, Li Z, et al. Increased hepatic and circulating interleukin-6 levels in human nonalcoholic steatohepatitis. Am J Gastroenterol. 2008; 103:1372-1379. [PubMed: 18510618]

41. Neuschwander-Tetri BA, Unalp A, Creer MH. Influence of local reference populations on upper limits of normal for serum alanine aminotransferase levels. Arch Intern Med. 2008; 168:663-66. [PubMed: 18362260]

42. Browning JD, Szczepaniak LS, Dobbins R, Nuremberg P, Horton JD, et al. Prevalence of hepatic steatosis in an urban population in the United States: impact of ethnicity. Hepatology. 2004; 40:1387-95. [PubMed: 15565570]

43. Saadeh S, Younossi ZM, Remer EM, Gramlich T, Ong JP, et al. The utililty of radiological imaging in nonalcoholic fatty liver disease. Gastroenterology. 2002; 123:745-50. [PubMed: 12198701]

44. Sharma P, Martin DR, Pineda N, Xu Q, Vos M, et al. Quantitation analysis of T2 correction in single voxel magnetic resonance spectroscopy of hepatic lipid fraction. J. Magn. Reson. Imaging. 2009; 29:629-35. [PubMed: 19243059]

45. Abdelmalek MF, Liu C, Shuster J, Nelson DR, Asal NR. Familial aggregation of insulin resistance in first-degree relatives of patients with nonalcoholic fatty liver disease. Clin. Gastroenterol. Hepatol. 2006; 4:1162-69. [PubMed: 16901766]

46. Saadeh S, Younossi ZM, Remer EM, Gramlich T, Ong JP, et al. The utililty of radiological imaging in nonalcoholic fatty liver disease. Gastroenterology. 2002; 123:745-50. [PubMed: 12198701]

47. Matulevicius S, Huff LC, Szczepaniak LS, Ayers CR, Budoff M, McColl R, Khera A, Peshock RM. Potential of electron beam computed tomography for coronary artery calcium screening to evaluate fatty liver: comparison with $1 \mathrm{H}$ magnetic resonance spectroscopy in the Dallas Heart Study. J Investig Med. Jun; 2011 59(5):780-6.

48. Greenland P, Alpert JS, Beller GA, Benjamin EJ, Budoff MJ, Fayad ZA, Foster E, Hlatky MA, Hodgson JM, Kushner FG, Lauer MS, Shaw LJ, Smith SC Jr, Taylor AJ, Weintraub WS, Wenger NK, Jacobs AK. American College of Cardiology Foundation/American Heart Association Task Force on Practice Guidelines. 2010 ACCF/AHA guideline for assessment of cardiovascular risk in asymptomatic adults: a report of the American College of Cardiology Foundation/American Heart Association Task Force on Practice Guidelines. Circulation. 2010; 122(25):e584-636. [PubMed: 21098428] 


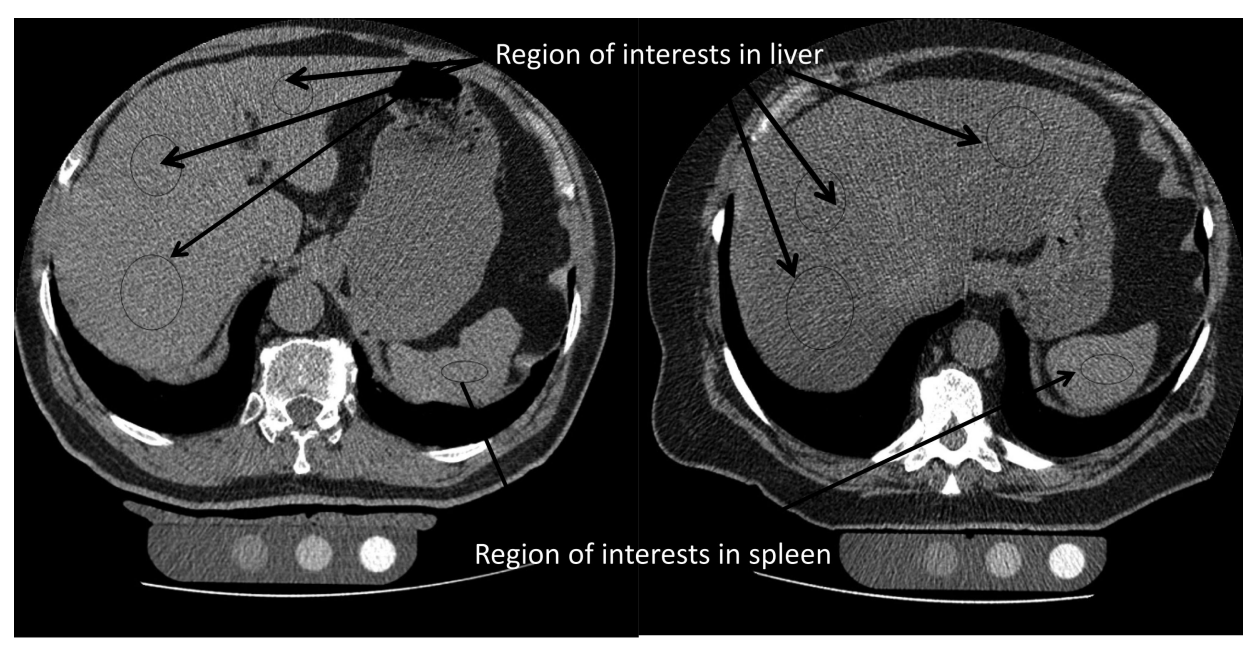

Figure 1.

Measurement of liver fat on Non Contrast Computed Tomography Scans (Regions of interest shown in the liver and spleen) 


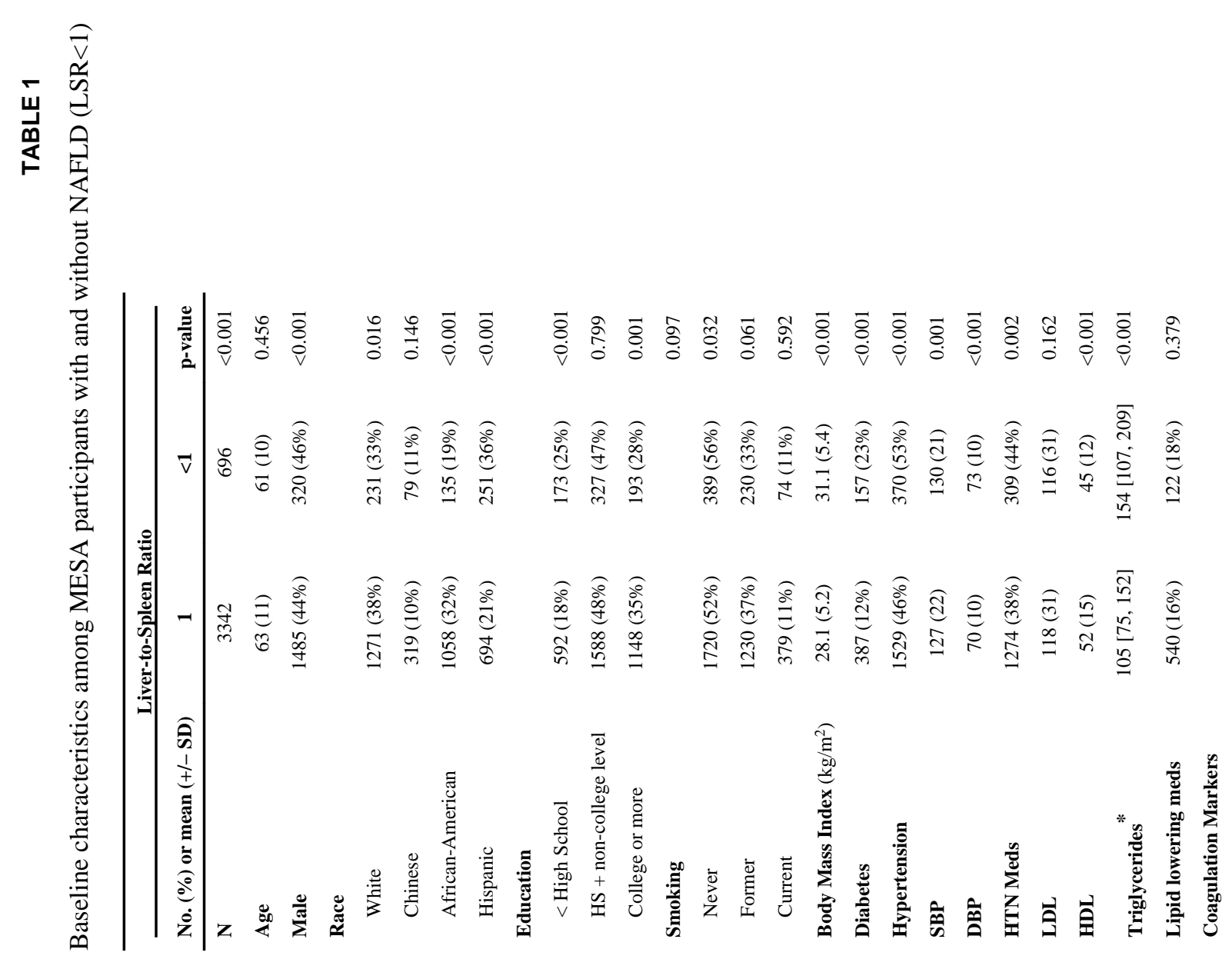

J Clin Exp Cardiolog. Author manuscript; available in PMC 2015 January 16. 


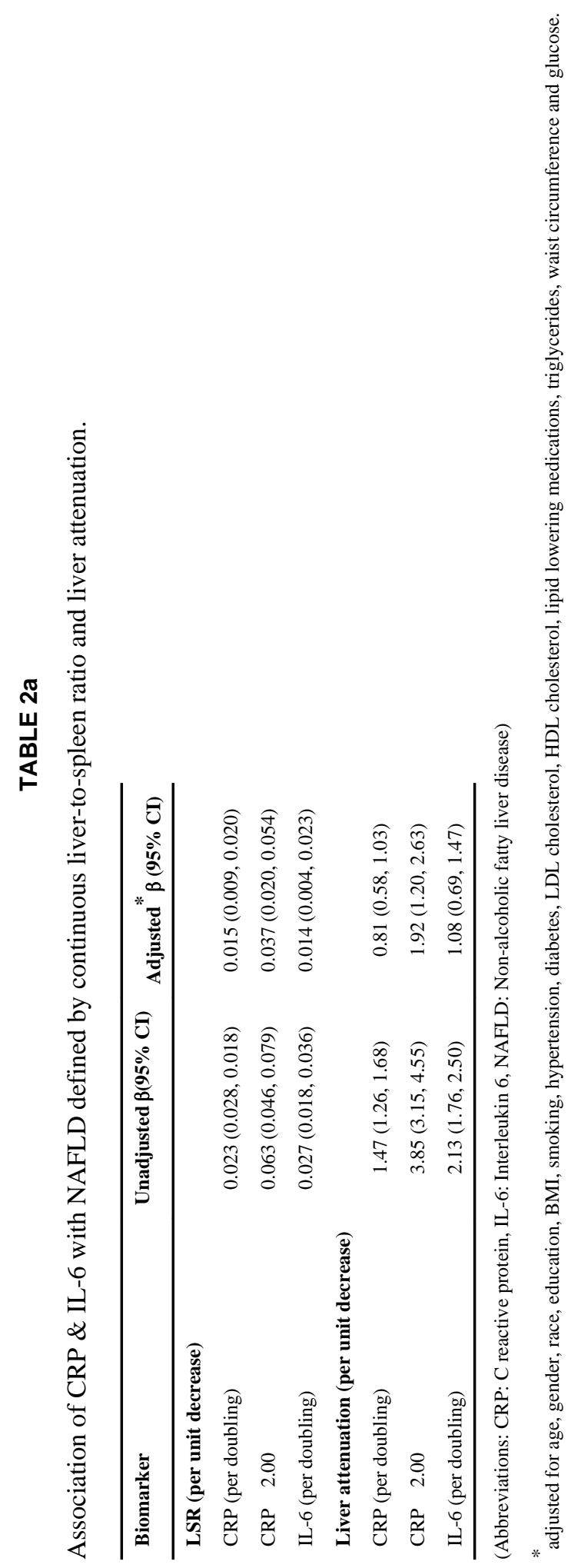

J Clin Exp Cardiolog. Author manuscript; available in PMC 2015 January 16. 


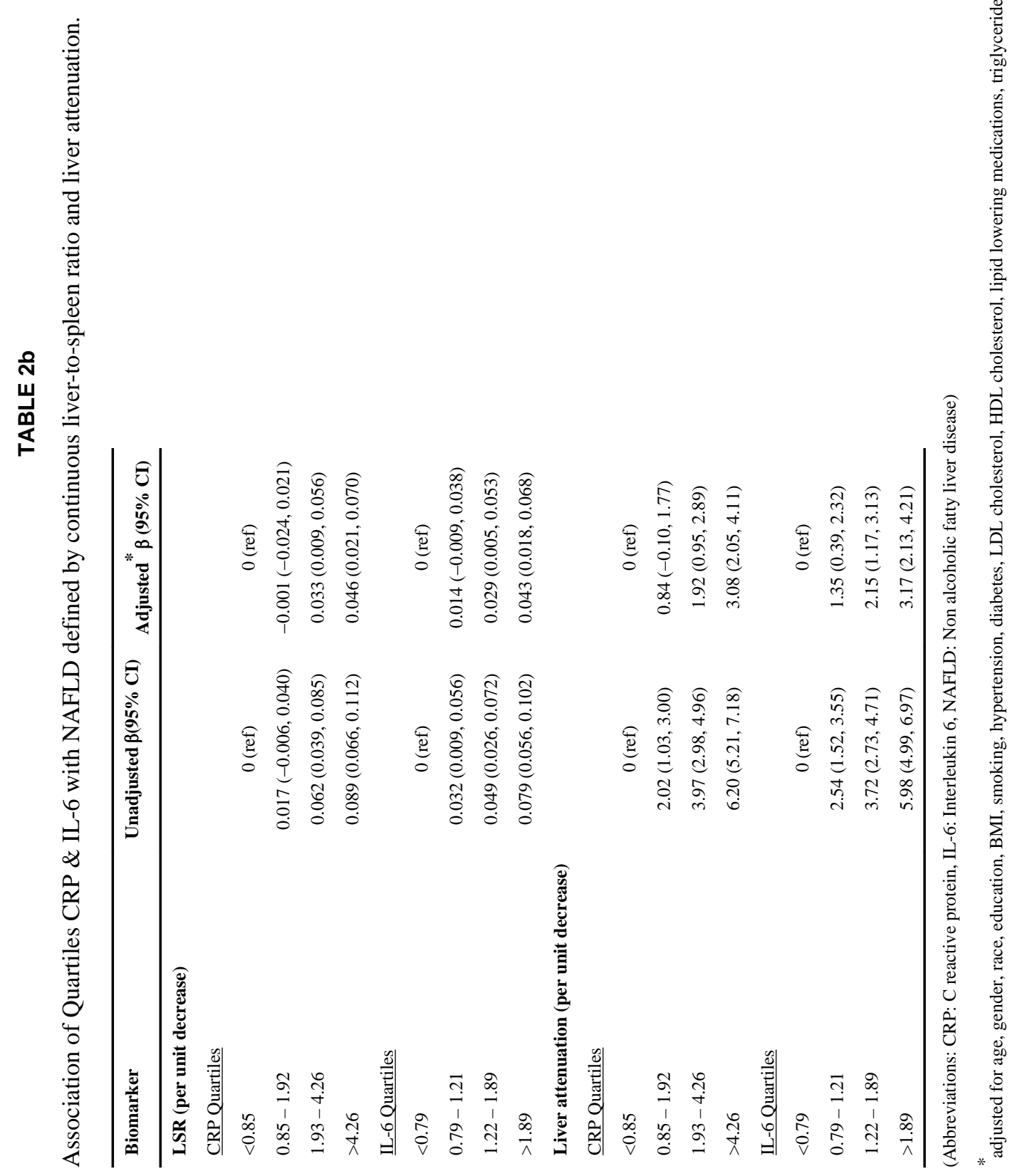




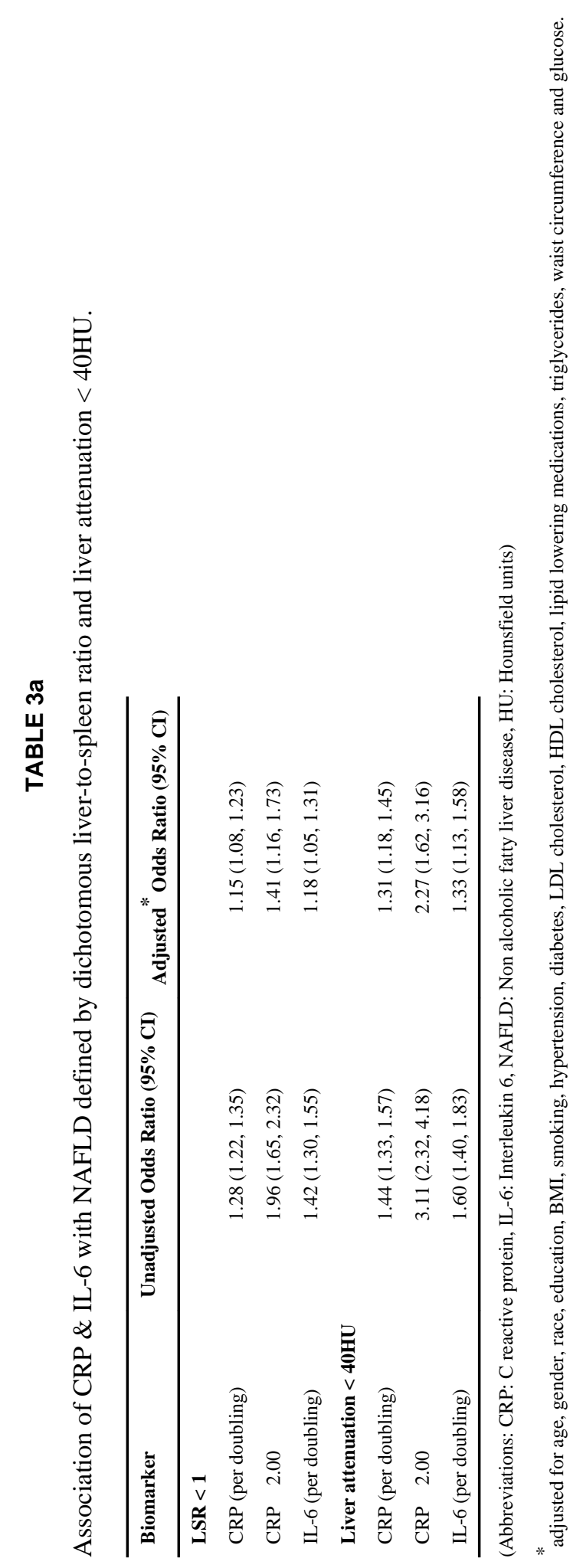

J Clin Exp Cardiolog. Author manuscript; available in PMC 2015 January 16. 
